\title{
Optimization of Leaf Area Estimation in a High-Density Apple Orchard Using Hemispherical Photography
}

\author{
Angela Knerl' ${ }^{1}$, Brendon Anthony ${ }^{1}$, Sara Serra, and Stefano Musacchi ${ }^{2}$ \\ Tree Fruit Research and Extension Center, Washington State University, \\ 1100 N. Western Avenue, Wenatchee, WA 98801
}

Additional index words. leaf area index, canopy, netting, CI-110 Plant Canopy Imager, nondestructive method

\begin{abstract}
Leaf area is evaluated as leaf area index (LAI), the ratio of leaf to ground area, and is known to be crucial to understanding forests and high-quality fruit production in orchards. Nondestructive tools have been available for decades that pair hemispherical photography with gap fraction theories to understand LAI. Those tools do not allow for rapid assessment in the field, and there is no standardized protocol to acquire accurate estimates yet. This experiment has developed an optimized method with the CID Plant Canopy Imager (CI-110) in a high-density apple orchard. This novel tool for LAI estimation allows image acquisition and processing in real time in the field. LAI assessments of hemispherical images were taken under five light environments, at three imaging heights, processed with two thresholding methods, and were compared with destructive LAI values for accuracy. The difference between estimated and destructive LAI ( $\triangle$ LAI) was determined for trees on an individual or grouped by a three tree basis. Estimations for triplet groupings were more accurate, and the significantly lower $\Delta \mathrm{LAI}$ in each treatment occurred for the no-net environment, $10 \mathrm{~cm}$ from the ground and processed with the Otsu threshold. When combined as triplet groupings, this methodology sequence yielded an LAI estimation with a $13 \%$ prediction error $(\triangle L A I=0.19)$. The use of the CI-110 with this methodology can give useful, real-time information regarding orchard canopies to address pruning and training decisions for high-quality fruit production.
\end{abstract}

As the Pacific Northwest fruit industry shifts to precision-based management strategies for their orchards, tools are needed to understand tree physiology in the orchard to optimize fruit quality. Leaf area index is the ratio between the summed area of one side of each leaf and the ground area the tree occupies (Bréda, 2003). LAI is an important physiological parameter within an orchard because it is easily manipulated with training and pruning, and can significantly affect canopy microclimates, water balance, gas exchange, and photosynthetic efficiency (Bréda, 2003; Robinson et al., 1991; Zhang et al., 2005). Correlations exist between LAI and canopy development (Liu et al., 2013), biomass (Goswami et al., 2015), ecosystem productivity (Bréda,

\footnotetext{
Received for publication 7 Feb. 2018. Accepted for publication 5 Apr. 2018.

This research was funded by the Washington Tree Fruit Research Commission with project number \# AP14-103A and WSDA Specialty Crop Block Grant Agreement Number: K1767.

Mention of a proprietary product or vendor does not constitute a guarantee or warranty of the product by Washington State University and does not imply its approval to the exclusion of other products or vendors that also may be suitable.

${ }^{1}$ These authors contributed equally to this work and are co-authors.

${ }^{2}$ Corresponding author. E-mail: Stefano.musacchi@, wsu.edu.
}

fraction models to estimate LAI and evaluate forest ecosystems and model ecophysiology (Bréda, 2003; Chianucci and Cutini, 2012).

LAI estimation techniques for forestry are used in other environments like orchards (Liu et al., 2013; Poblete-Echeverría et al., 2015; Wünsche et al., 1995), but they must be adjusted and optimized because the trees are in rows and can be much smaller than in forests. The modern choice for new orchards is high-density planting (HDP) at 2000-4000 trees/ha with planting densities as high as $0.75 \mathrm{~m} \times 3.00 \mathrm{~m}$. HDP is characterized by small and narrow canopies where a large part of the foliage is fully exposed to the sun as typically arranged to a spindle or V system (Musacchi and Green, 2017). However, the use of estimation tools in both environments has opportunities for error throughout the application.

Sources of error in LAI estimation occur during image acquisition, or when analyzing photographs (Chianucci and Cutini, 2012; Rich, 1988). Guidelines, methods, and software for forestry applications were reviewed and suggested in Chianucci and Cutini (2012), Jonckheere et al., (2004), and Bréda (2003). Ideal light conditions for measurements are uniform like overcast, early morning, or evening skies (Lakso, 1976). Cutini and Varallo (2006) acquired images of two forest species at heights of $1 \mathrm{~m}$ from the ground. After images are acquired, software like WinSCANOPY are available to enable automatic pixel classification to estimate LAI. However, there is no standardized methodology, tool, or model for groundbased LAI estimation for forests or orchards (Jonckheere et al., 2004; Woodgate et al., 2012).

Therefore, a streamlined methodology and sampling strategy is needed for each instrument and environment to limit bias and create reproducible and consistent results. The Digital Plant Canopy Imager CI-110 (CID Bio-Science, Inc., Camas, WA) was developed for rapid estimations of LAI by combining light sensors, hemispherical photography, and processing software in one tool. The CI-110 LAI estimation tool was selected in this study for its simplicity and data accessibility through an associated tablet with onscreen viewing for accurate image acquisition and portability (Fig. 1). The CI-110 differs when compared with other hemispherical photography analysis systems because it can acquire and process images instantly in the field without additional external software, like WinSCANOPY (Regents Instruments, Inc., Quebec, Canada) and HemiView (Delta-T Devices, Ltd., Cambridge, UK) (Bréda, 2003). Instead, images acquired by CI-110 are processed by the built-in models Otsu or Entropy Crossover provided in CID Plant Canopy Analysis software (CID Bio-Science, Inc.). In Bréda's (2003) review on ground-based LAI instruments, it was noted that there were no published data comparing the CI-110 and its integrated software to other tools. Since then, studies have demonstrated the accuracy of the CI-110 in forestry estimations (Keane et al., 2005), but no literature was found 


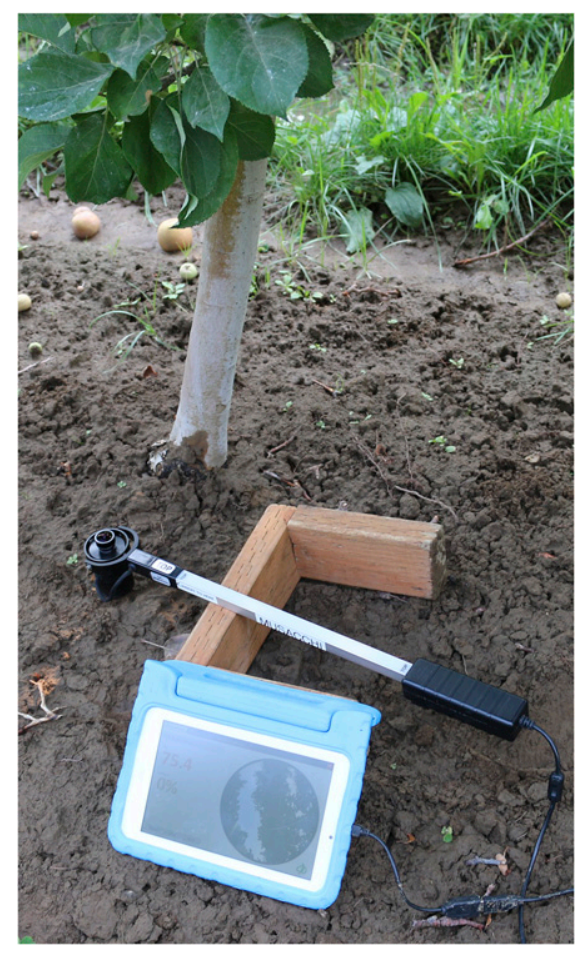

Fig. 1. The Digital Plant Canopy Imager CI-110 set up in the field features a self-leveling camera attached to a bar with 24 photosynthetically active radiation sensors and displays measurements in real time on an attached tablet through CI-110 Plant Canopy Analysis System software.

regarding the use of this tool in tree fruit orchards. Orchards are very different from forests given their density, arrangement, and tree architecture. The objective of this experiment is to determine an optimal methodology for light conditions, height from ground, and leaf distinguishing thresholds for the CI-110 to estimate LAI accurately within an apple HDP orchard.

\section{Materials and Methods}

Experimental design and equipment. Nine 'WA38' apple (Malus $\times$ domestica Borkh.) trees in an orchard planted $(0.9 \mathrm{~m} \times 3.0 \mathrm{~m})$ in 2013 near Rock Island, WA (47.311531 N, -120.068469 W) were selected in 2016 for LAI measurements. Trees were grafted on M.9 Nic29 (Nic29) rootstocks, trained as a spindle system, were imaged, and evaluated as nine single trees (individuals). Later, during image processing, three groups (triplets) were formed of the nine measured trees to assess a possible approach to improve the accuracy of the estimates. The triplet grouping approach was considered because the branches of trees planted at high density tend to overlap and occupy part of the ground area of their neighbor trees. To facilitate grouping, there was an unrecorded guard tree separating triplets in the field. All nine trees after harvest (no fruit included) were sequentially imaged on 23 Sept. 2016 [photosynthetically active radiation $(P A R)$ : $200-506 \mu \mathrm{mol} \cdot \mathrm{m}^{-2} \cdot \mathrm{s}^{-1}$ ],
27 Sept. $2016\left(P A R: 80-108 \mu \mathrm{mol} \cdot \mathrm{m}^{-2} \cdot \mathrm{s}^{-1}\right)$ and 3 Oct. $2016\left(P A R\right.$ : $\left.91-337 \mu \mathrm{mol} \cdot \mathrm{m}^{-2} \cdot \mathrm{s}^{-1}\right)$, with the CID CI-110 Canopy Imager (CID Bio-Science, Inc.) for a nondestructive LAI estimation at early morning. The measurements were replicated three times as the $3 \mathrm{~d}$ mentioned above, to equalize possible different light conditions. The canopy imager captures hemispherical photographs with its $150^{\circ}$ fisheye lens and is used for photographing canopies at the ground level (Fig. 1). The CI-110 contains 24 PAR sensors arranged in a bar and calculates LAI through Norman and Campbell's (1989) gap fraction inversion procedure. Images are divided into sections through azimuth and zenith lines. Foliage pixels are discerned from sky pixels with thresholding methods. The Entropy Crossover method places pixels in classes based on probability functions and finds the maximum point of randomness for each function to assign class definition (Jonckheere et al., 2005). The Otsu threshold is determined through a least square methodology that distinguishes between two clusters of pixels in a histogram (Fang et al., 2009; Sezgin and Sankur, 2004). The resulting foliage pixels are summed across all sections and divided by sky pixels to determine the LAI. The software uses formulaic expressions for calculating the transmission coefficient, LAI, and the mean foliage inclination angle of the canopy and can be found in the operator's manual (CID Bio-Science, Inc.).

Although the CI-110 contains its own quantum sensor ceptometer, an additional quantum LI-190R PAR sensor $(q P A R)$ (LI-COR, Inc., Lincoln, NE) measured light intensity under the net (UN PAR), $50 \mathrm{~cm}$ from the trunk and unobstructed by foliage shade. This sensor also measured light above canopy ( $L A C P A R)$ at $1 \mathrm{~m}$ above the ground outside the canopy. These measurements were taken to evaluate the incident light and the amount of light being transmitted through the shade nets with each net type. The CI-110 does require manual input of $L A C P A R$ for its calculations and the second sensor $(q P A R)$ was used instead of the CI-110 ceptometer to sample the incident light (LAC PAR and UN $P A R)$ concurrently with CI-110 acquiring images of tree canopies.

Treatments. To determine the optimal methodology for image acquisition and leaf area estimation, three variables were assessed for their effect on LAI quantification accuracy: light environment, imaging height and processing threshold. Four light environments were artificially created over the trees with shade nets to standardize light conditions (Green-Tek, Janesville, WI). The blue nets used were manufactured with $30 \%$ and $60 \%$ of shading effect in respect to $P A R$ reduction, and pearl nets were rated to shade $30 \%$ and $50 \%$. Blue and pearl nets were selected among all possible colored antihail nets as they were most likely to mimic uniform overcast or clear sky conditions ideal for image acquisition. Therefore, the five light environment treatments were: no net (control), blue $30 \%$, blue $60 \%$, pearl $30 \%$, and pearl $50 \%$. Each $8 \mathrm{~m} \times 9 \mathrm{~m}$ net was draped over the top trellis wire to cover a triplet of $\approx 3 \mathrm{~m}$ tall trees. Measurements were taken during the early morning to avoid solar interference during imaging. Image acquisition heights were 10,20 , and $40 \mathrm{~cm}$ from the ground on the west side of the tree $20 \mathrm{~cm}$ from the trunk. On average, distance between the lens and the first tree branch was 45,35 , and $15 \mathrm{~cm}$ for each respective acquisition height. The self-leveling camera was facing the canopy, with the tool oriented north according to the software's compass to ensure consistent images for comparison.

Images were processed with the software provided by CID (CID Bio-Science, Inc.). The outer $30^{\circ}$ of zenith was excluded and tree trunks were excluded by deselecting appropriate azimuth to reduce estimation of wood and LAI of trees in other rows. The extinction coefficient, or light penetration through the canopy dependent on leaf area, was set to 0.6 as appropriate for apples (Faust, 1989). Values for $U N P A R$ and $L A C P A R$ for the no-net treatment were entered into the program for solar position at the time of imaging. Finally, each gap fraction threshold model was selected, and LAI was noted for Otsu and Entropy Crossover. Color selection, brightness, and contrast were left unaltered to ensure limited operator bias in processing. Each round of photography produced 270 images of the combinations of 5 light environments $\times 3$ heights $\times 2$ thresholds $\times 9$ trees. With three measurement days, 810 images were processed yielding three replications of 30 methodology treatment combinations per each of the nine trees to compare with the destructive LAI value. The average of these three replications was used as the LAI value for mean comparisons.

Leaf area quantification. Nine mesh, $1.8 \mathrm{~m} \times$ $7.0 \mathrm{~m}$ bags cut out of $20 \%$ pearl shade net (Green-Tek), were placed around each tree for leaf collection. The defoliation bags were set up after imaging on 21 Oct. 2016, before the initiation of leaf drop on 14 Nov. 2016. Each net was hung over the top wire and draped around a tree. The sides were sewn shut and bottom tied closed with a steel yarn needle and twisted mason line. The defoliation bags collected leaves as they naturally abscised.

Leaf collections took place every 7-10 d as leaves naturally abscised. Total fresh weights for each collection were recorded and subsamples of 200 leaves per collection were separated and weighed. The freshest leaves of the sample's representative size were selected for the subsample. If 200 leaves were not available per collection, then a sample rounded to the nearest five was chosen. Leaves were scanned with the LI-3100C Area Meter (LI-COR, Inc.). Subsample weight and area were used to extrapolate the area of leaves in the total collection [items (1) and (4)]. This process was repeated across four collections until all the trees' leaves were recovered. Then, total leaf area was summed for the four collections and divided 
by the ground area for LAI [item(7)]. There was a $6 \%$ difference in area between freshly pruned leaves and bagged abscised leaves as measured for a similar plot of 'WA38' trees. This small difference means there was potential leaf degradation for defoliated collection, but it was within the margin of morphological variation based on $7 \%$ and $11 \%$ standard deviation of leaf area for fresh and fallen leaves.

Destructive LAI was calculated through the following procedure:

1. Subsample\% $=[$ subsample fresh weight $(\mathrm{SFW})(\mathrm{g}) /$ total fresh weight $(\mathrm{TFW})(\mathrm{g})] \times 100$

2. Total no. of leaves in sample $=[$ no. of subsample leaves $\times(\mathrm{TFW})(\mathrm{g})] / \mathrm{SFW}(\mathrm{g})$

3. Average leaf weight $(\mathrm{mg})$ $=[\mathrm{SFW}(\mathrm{g}) \times 1000]$ /no. of leaves in subsample

4. Total leaf area(collection) $\left(\mathrm{cm}^{2}\right)$ $=$ subsample leaf area scanned $\left(\mathrm{cm}^{2}\right) /$ (subsample\%/100)

5. Canopy removed (collection) $\left(\mathrm{m}^{2}\right)$ $=\left[\right.$ total leaf area $\left.(\mathrm{LA})\left(\mathrm{cm}^{2}\right) \times 0.0001\right]$

6. Total canopy(sum of four collections) $=\sum \mathrm{LA}\left(\mathrm{m}^{2}\right)($ Collection 1 : Collection 4$)$

7. Leaf area index(LAI) $=$ total canopy $\left(\mathrm{m}^{2}\right) /$ ground area $\left(\mathrm{m}^{2}\right)$

Ground area allotted for each tree was based on the $3 \mathrm{ft} \times 10 \mathrm{ft}$ planting density, or
$30 \mathrm{ft}^{2}\left(2.78 \mathrm{~m}^{2}\right)$ per tree. Once all destructive LAI values were calculated, they were subtracted from the estimated LAI for each tree to determine the difference in LAI:

$\Delta \mathrm{LAI}_{\text {individual }}=\left|\mathrm{LAI}_{\text {estimated }}-\mathrm{LAI}_{\text {destructive }}\right|$

When estimated on a "triplet" basis, LAI destructive values and estimations were averaged across the three groups of three trees (T1-T3, T4-T6, T7-T9) before they were subtracted from each other:

$$
\begin{aligned}
& \Delta \mathrm{LAI}_{\text {triplet }}=\mid \text { Average } \sum \mathrm{LAI}_{\text {estimated }} \mid \\
& -\mid \text { Average } \sum \mathrm{LAI}_{\text {destructive }} \mid
\end{aligned}
$$

Statistical analysis. Statistical analyses were conducted using SAS Enterprise Guide 7.1 (SAS Institute, Inc., Cary, NC). Individual and triplet $\triangle$ LAI were assessed for normality with Proc UNIVARIATE using the Anderson-Darling $P$-test values for significance. $\Delta \mathrm{LAI}_{\text {individual }}$ data were normalized through a square root transformation. No transformations were needed for $\Delta \mathrm{LAI}_{\text {triplet }}$ data. The effect of shade net, imaging height, and threshold on the difference between estimated and destructive LAI for individual and triplet values were assessed for significance with separate three-way factorial analysis of variance (ANOVA) with the Proc GLM type III sum of squares test. LAI estimation measurements across the $3 \mathrm{~d}$ were averaged and used in the ANOVA. Post hoc means discrimination was performed using pairwise comparisons with the Student-Newman-Keuls' test to assign differing letter groups when the model was significant. Minimal significance level was at $P$ value $<0.05$.

Sampling conditions. Light conditions on sampling days ranged from 80 to 506 $\mu \mathrm{mol} \cdot \mathrm{m}^{-2} \cdot \mathrm{s}^{-1} P A R$ above the canopy and from 19 to $114 \mu \mathrm{mol} \cdot \mathrm{m}^{-2} \cdot \mathrm{s}^{-1} P A R$ under the nets (data not shown). Skies were uniformly overcast on 23 Sept. 2016, and uniformly clear on 27 Sept. 2016 and 3 Oct. 2016. Darkest conditions, with respect to $P A R$, were under the blue $30 \%$ net and brightest under the nonet environment. The pearl $50 \%$ net created a highly reflective background, excessively illuminating and distorting portions of the canopy when compared with blue (Fig. 2A-D). Direct sunlight transmission through the canopy onto the lens, or sunflecks, were avoided by measuring early in the morning.

\section{Results}

LAI estimation. Ground area for each tree was $2.78 \mathrm{~m}^{2}$ and total canopy removed for each tree averaged $4.42 \mathrm{~m}^{2}$. Average destructive LAI was 1.59 and ranged from 1.01 to 2.18 (data not shown). The treatment combinations (net $\times$ height $\times$ threshold) that resulted in the lowest significant difference between estimated $\mathrm{LAI}_{\text {individual }}$ and destructive $\mathrm{LAI}_{\text {individual }}$ ( $\triangle \mathrm{LAI})$ were Otsu-10 cm-blue 60\% (0.44), Otsu-10 cm-pearl 50\% (0.42), Entropy-10
A

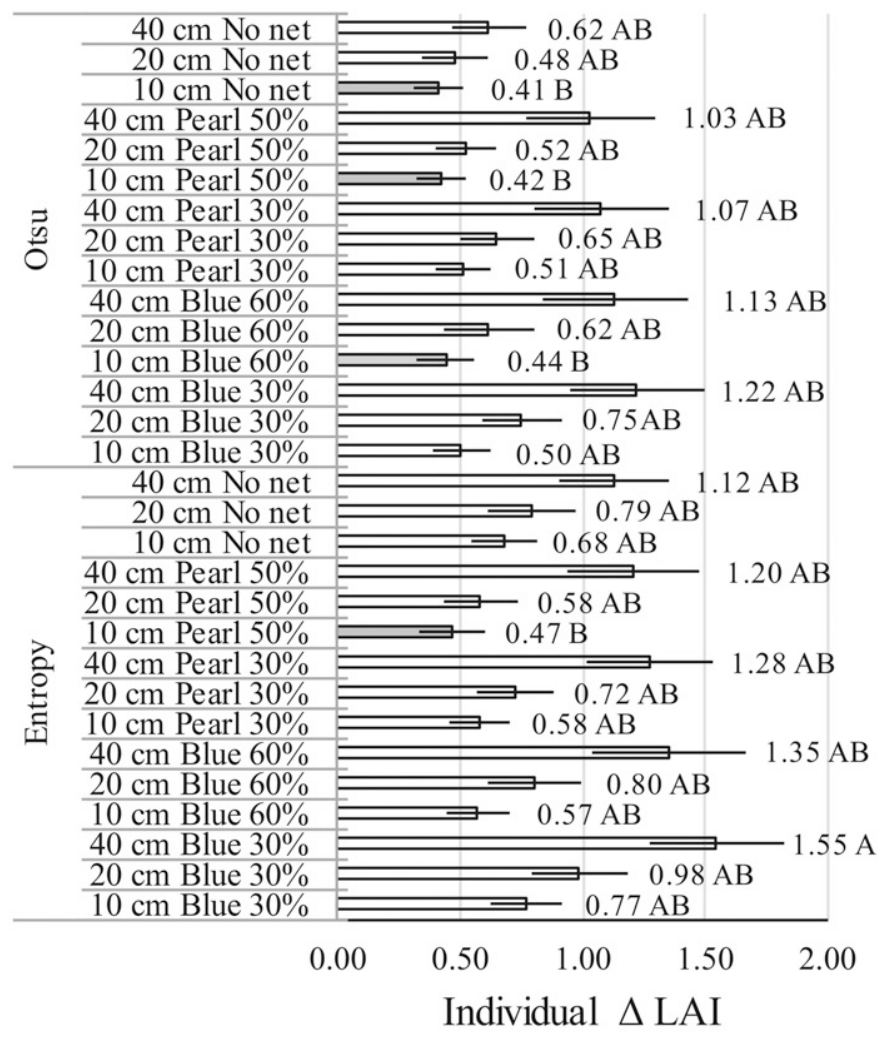

B

Fig. 2. A comparison of the difference between estimated leaf area index (LAI) and defoliated LAI for 30 combinations of light environment, imaging height, and leaf distinguishing thresholds for $(\mathbf{A})$ individual trees (estimated $\mathrm{LAI}_{\text {individual }}$ - destructive $\left.\mathrm{LAI}_{\text {individual }}\right)$ and $(\mathbf{B})$ and triplets $\left(\mid\right.$ Average $\sum \mathrm{LAI}$ estimated $\mid$ Average $\left.\sum L \mathrm{LI}_{\text {destructive }} \mid\right)$. Significance established with an analysis of variance proc GLM procedure and type III sum of squares in SAS. Mean separation by Student-Newman-Keuls' post hoc pairwise tests at $P<0.05$. Bars are Standard Error (SE). Columns identifying the best combinations are in gray. 
cm-pearl 50\% (0.47), and Otsu-10 cm-no net (0.41; Fig. 2A). Of these, Otsu-10 $\mathrm{cm}-$ no net had the lowest $\Delta \mathrm{LAI}_{\text {individual }}$ of $0.41 \pm 0.11_{\text {(SE) }}$ with $30 \%$ LAI estimation error. On an individual tree basis, the shading environment, imaging height, and threshold selection that resulted in the lowest $\Delta \mathrm{LAI}_{\text {individual }}$ values when analyzed separately (Table 1 ) were the no net $(0.68$ at $50 \%$ estimation error, even if not significantly different between other shading conditions), $10 \mathrm{~cm}$ (0.54 at 38\% estimation error), and Otsu threshold (0.69 at 50\% estimation error). Imaging height and threshold selection had a significant influence on $\triangle \mathrm{LAI}_{\text {individual }}$ (Table 1), whereas no significant differences between shading environments occurred on single-tree estimations (Table 1). Change in imaging height resulted in the

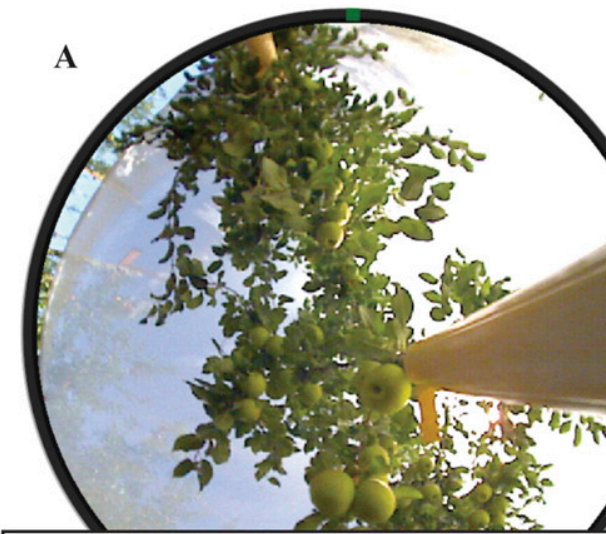

Pearl $50 \%$ at $10 \mathrm{~cm}$ - high light under net
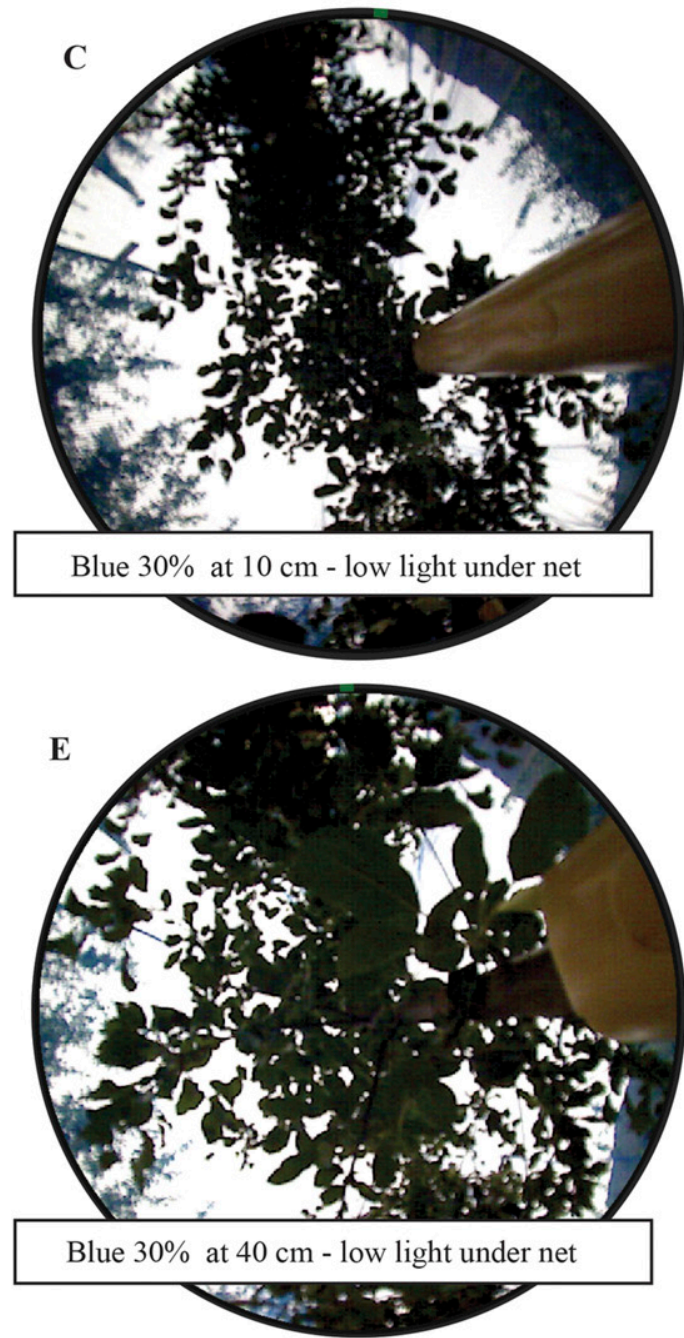
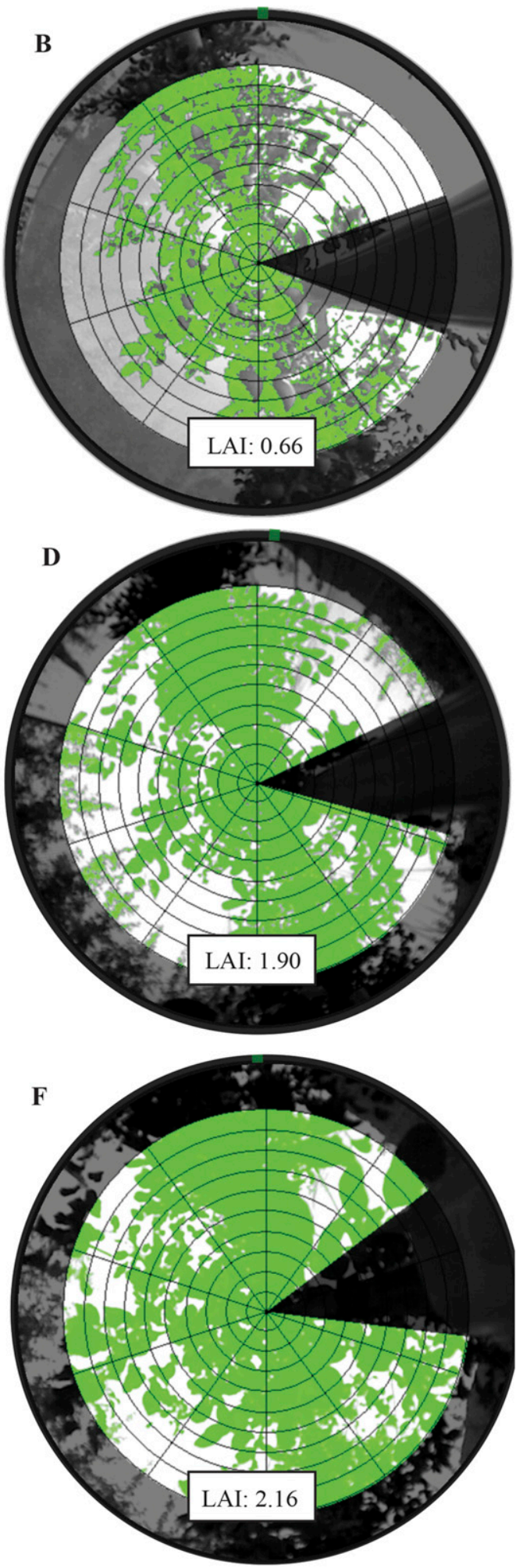

Fig. 3. The effect of light intensity, shade netting, and height on leaf area index (LAI) through pairs of hemispherical images (A-B, C-D, and $\mathbf{E}-\mathbf{F})$ before and after processing with the CI-110 Plant Canopy Analysis System for 'WA38' apple trees. Pairs (A and B) and (C and D) demonstrate the effect of light intensity during image acquisition. Images (A and $\mathbf{B}$ ) showcase the leaf washout effect because of direct solar interference and the high reflectance of the pearl $50 \%$ shade net. Under lower light intensity, foliage detection by the software is enhanced $(\mathbf{C}$ and $\mathbf{D})$. Pairs $(\mathbf{C}$ and $\mathbf{D})$ and $(\mathbf{E}$ and $\mathbf{F})$ demonstrate the effect imaging height has on LAI, it is artificially inflated from $10 \mathrm{~cm}(\mathbf{D})$ to $40 \mathrm{~cm}(\mathbf{F})$. 
widest range of $\Delta \mathrm{LAI}_{\text {individual }}$ across the different treatments (Fig. 3C-F). An average 0.62 increase in $\triangle \mathrm{LAI}_{\text {individual }}$ occurred from the $10 \mathrm{~cm}$ to the $40 \mathrm{~cm}$ height on single-tree estimations (Table 1).

When analyzing $\triangle \mathrm{LAI}$ for triplet groupings, the Otsu-10 cm-no net combination resulted in the lowest significant $\Delta \mathrm{LAI}_{\text {triplet }}$ of $0.19 \pm 0.09_{(\mathrm{SE})}, 13 \%$ LAI estimation error (Fig. 2B). The lowest $\Delta \mathrm{LAI}_{\text {triplet }}$ mean values when factors were analyzed separately were the no net $(0.61$ at $39 \%$ estimation error), $10 \mathrm{~cm}(0.43$ at $28 \%$ estimation error), and Otsu threshold ( 0.61 at $40 \%$ error) (Table 1$)$. Significant differences occurred across each of the shading environments, imaging heights, and threshold selections (Table 1). There was a significant interaction $(P=0.038)$ between net and threshold in the triplet analysis and could be because of the fewer df in comparison with the individual values (Table 1). Measurements under the no-net shading environment resulted in the most accurate estimations when compared with the other treatments. Blue $30 \%$ images resulted in significantly higher estimations of $\mathrm{LAI}_{\text {triplet }}$ compared with the other shade nets and nonet treatment (Fig. 2B). $\Delta \mathrm{LAI}_{\text {triplet }}$ increased 0.72 as imaging height increased from 10 to $40 \mathrm{~cm}$ from the ground. Otsu processing resulted in significantly lower $\Delta \mathrm{LAI}_{\text {triplet }}$ values than Entropy.

\section{Discussion}

Favorable light conditions are the first step to ensuring accurate LAI estimations. Sunflecks and high levels of irradiance can wash out foliage pixels (Fig. 3A-B), leading to underestimations of leaf area. Lakso (1976) stated that to avoid sunlit leaves interfering with image processing, sampling

Table 1. The effect of light conditions, imaging height, and leaf distinguishing thresholds on the difference between estimated leaf area index (LAI) and defoliated LAI for individual trees (individual $\triangle \mathrm{LAI}=$ |estimated $\mathrm{LAI}_{\text {individual }}-$ destructive $\left.\mathrm{LAI}_{\text {individual }}\right)$ and triplets (triplet $\Delta \mathrm{LAI}=\mid$ Average $\sum \mathrm{LAI}_{\text {estimated }} \mid-$ |Average $\left.\sum \mathrm{LAI}_{\text {destructive }} \mid\right)$ of 'WA38' apple trees in 2016.

\begin{tabular}{lcc}
\hline Variable & Individual $\Delta$ LAI & Triplet $\Delta$ LAI \\
\hline Net (color and shading) & & \\
Blue 30\% & 0.96 & $0.92^{z} \mathrm{~A}$ \\
Blue 60\% & 0.82 & $0.77 \mathrm{~B}$ \\
Pearl 30\% & 0.80 & $0.76 \mathrm{~B}$ \\
Pearl 50\% & 0.70 & $0.64 \mathrm{BC}$ \\
No net & 0.68 & $0.61 \mathrm{C}$ \\
Significance & $\mathrm{NS}$ & $<0.0001$ \\
Height $(\mathrm{cm})$ & & \\
10 & $0.54 \mathrm{~B}$ & $0.43 \mathrm{C}$ \\
20 & $0.69 \mathrm{~B}$ & $0.64 \mathrm{~B}$ \\
40 & $1.16 \mathrm{~A}$ & $1.15 \mathrm{~A}$ \\
Significance & $<0.0001$ & $<0.0001$ \\
Threshold & & \\
Otsu & $0.69^{\mathrm{z}} \mathrm{b}$ & $0.61 \mathrm{~B}$ \\
Entropy & $0.90 \mathrm{a}$ & $0.87 \mathrm{~A}$ \\
Significance & 0.0023 & $<0.0001$ \\
Net $\times$ height & $\mathrm{NS}$ & $\mathrm{NS}$ \\
Net $\times$ threshold & $\mathrm{NS}$ & 0.038 \\
Height $\times$ threshold & $\mathrm{NS}$ & $\mathrm{NS}$ \\
Net $\times$ height $\times$ threshold & $\mathrm{NS}$ & $\mathrm{NS}$ \\
\hline
\end{tabular}

${ }^{\mathrm{z}}$ Mean separation by Student-Newman-Keuls' post hoc pairwise tests at $P<0.01$ (lowercase) or $P<0.001$ (uppercase).

${ }^{\mathrm{y}}$ Significance established with an analysis of variance with proc GLM procedure and type III sum of squares in SAS.
Modern orchards need streamlined tools and methodologies to enable rapid evaluations of canopy size to ensure optimal light interception and high fruit quality production. The most accurate results were obtained when images were taken before sunrise $(P A R$ $\left.<500 \mu \mathrm{mol} \cdot \mathrm{m}^{-2} \cdot \mathrm{s}^{-1}\right)$, low to the ground $(10$ $20 \mathrm{~cm}$ ), processed with the Otsu threshold, and when trees were estimated in groups of three because of the difficulty of estimating LAI on single plants (Chianucci and Cutini, 2012). Previous literature states that an optimal LAI value for apple orchards is $1.80 \pm$ 0.25 (Jackson, 1978). This tool applied with the best-case methodology resulted in $\triangle \mathrm{LAI}$ of 0.19 with $13 \%$ error on triplets. In respect to the accepted \pm 0.25 range for optimal LAI stated by Jackson (1978), the CI-110 can give a sufficient understanding of canopy size in a plot to guide leaf area management. With this all-in-one tool and method, a grower could refine light penetration through mechanical pruning in June to maximize flower bud development (Marini and Barden, 1982; Saure, 1987). The use of the CI-110 with this methodology can provide useful, real-time information regarding orchard canopies to inform pruning and training decisions for consistent high-quality fruit production. If optimized in other agricultural settings, its precision and accuracy could also estimate LAI in other valuable crops.

\section{Literature Cited}

Barritt, B.H. 1989. Influence of orchard system on canopy development, light interception and production of third-year Granny Smith apple trees. Acta Hort. 243:121-130.

Bréda, N.J. 2003. Ground-based measurements of leaf area index: A review of methods, instruments and current controversies. J. Expt. Bot. 54:2403-2417.

Chianucci, F. and A. Cutini. 2012. Digital hemispherical photography for estimating forest canopy properties: Current controversies and opportunities. IForest (Viterbo) 5:290-295.

Cutini, A. and A. Varallo. 2006. Estimation of foliage characteristics of isolated trees with the Plant Canopy Analyzer LAI-2000. Ecology 1:49-56.

Fang, M., G. Yue, and Q. Yu. 2009. The study on an application of Otsu method in canny operator. Proc. 2009 Intl. Symp. Info. Processing, 109-112.

Faust, M. 1989. Physiology of temperate zone fruit trees. Wiley, Hoboken, NJ.

Goswami, S., J.A. Gamon, S. Vargas, and C.E. Tweedie. 2015. Relationships of NDVI, biomass, and leaf area index (LAI) for six key plant species in Barrow, Alaska. PeerJ PrePrints, $<$ https://doi.org/10.7287/peerj.preprints.913v1>.

Heinicke, A.J. 1964. The microclimate of fruit trees III the effect of tree size on light penetration and leaf area in red delicious apple trees. Proc. Amer. Soc. Hort. Sci. 85:33-41.

Jackson, J.E. 1978. Utilization of light resources by HDP systems. Acta Hort. 65:61-70.

Jonckheere, I., S. Fleck, K. Nackaerts, B. Muys, P. Coppin, M. Weiss, and F. Baret. 2004. Review of methods for in situ leaf area index determination Part I: Theories, sensors and hemispherical photography. Agr. For. Meteorol. 121:19-35.

Jonckheere, I., K. Nackaerts, B. Muys, and P. Coppin. 2005. Assessment of automatic gap fraction estimation of forests from digital hemispherical photography. Agr. For. Meteorol. 132:96-114. 
Keane, R.E., E.D. Reinhardt, J. Scott, K. Gray, and J. Reardon. 2005. Estimating forest canopy bulk density using six indirect methods. Can. J. For. Res. 35:724-739.

Lakso, A.N. 1976. Characterizing apple tree canopies by fisheye photography. HortScience 11:404-405.

Lakso, A.N. 1980. Correlations of fisheye photography to canopy structure, light climate, and biological responses to light in apple trees. J. Amer. Soc. Hort. Sci. 105:43-46.

Liu, C., S. Kang, F. Li, S. Li, and T. Du. 2013. Canopy leaf area index for apple tree using hemispherical photography in arid region. Scientia Hort. 164:610-615.

Marini, R.P. and J.A. Barden. 1982. Growth and flowering of vigorous apple tree affected by summer and dormant pruning. J. Amer. Soc. Hort. Sci. 107:34-39.

Musacchi, S. and D. Green. 2017. Innovations in apple tree cultivation to manage crop load and ripening, p. 195-237. In: K. Evans (ed.). Achieving sustainable cultivation of apples. Burleigh Dodds Science Publishing, Cambridge, UK.

Norman, J.M. and G.S. Campbell. 1989. Canopy structure, p. 301-325. In: R.W. Pearcy, J.
Ehlringer, H.A. Mooney, and P.W. Rundel (eds.). Plant ecology: Field methods and instrumentation. Chapman \& Hall, London, UK.

Poblete-Echeverría, C., S. Fuentes, S. OrtegaFarias, J. Gonzalez-Talice, and J.A. Yuri. 2015. Digital cover photography for estimating leaf area index (LAI) in apple trees using a variable light extinction coefficient. Agr. For.: Sensors, Technologies Procedures 15:2860-2872.

Rich, P.M. 1988. Video image analysis of hemispherical canopy photography. Proc. First Special Wkshp. Videography, 84-95.

Robinson, T., E. Seeley, and B. Barritt. 1983. Effect of light environment and spur age on "Delicious" apple fruit size and quality. J. Amer. Soc. Hort. Sci. 108:855-861.

Robinson, T.L., A.N. Lakso, and Z. Ren. 1991. Modifying apple tree canopies for improved production efficiency. HortScience 26:1005-1012.

Robinson, T.L., J. Wünsche, and A. Lakso. 1993. The influence of orchard system and pruning severity on yield, light interception, conversion efficiency, partitioning index and leaf area index. Acta Hort. 349:123-128.

Saure, M.C. 1987. Summer pruning effect on apple: A review. Scientia Hort. 30:253-282.
Sezgin, M. and B. Sankur. 2004. Survey over image thresholding techniques and quantitative performance evaluation. J. Electron. Imaging 13(1):146-165.

Verheij, E.W.M. and F.L.J.A.W. Verwer. 1973. Light studies in a spacing trial with apple on a dwarfing and a semi-dwarfing rootstock. Scientia Hort. 1(1):25-42.

Woodgate, W., M. Soto-Berelov, L. Suarez, S. Jones, M. Hill, P. Wilkes, C. Axelsson, A. Haywood, and A. Mellor. 2012. Searching for the optimal sampling design for measuring LAI in an upland rainforest. Proc. 2012 Geospatial Sci. Res. Symp. GSR2.

Wünsche, J.N., A.N. Lakso, and T.L. Robinson. 1995. Comparison of four methods for estimating total light interception by apple trees of varying forms. HortScience 30:272-276.

Wünsche, J.N. and J.W. Palmer. 1997. Comparison of non-destructive methods of estimating leaf area in apple tree canopies. Acta Hort. 451: 701-708.

Zhang, Y., J.M. Chen, and J.R. Miller. 2005. Determining digital hemispherical photograph exposure for leaf area index estimation. Agr. For. Meteorol. 133:166-181. 